\title{
The three second consultation
}

\section{John Launer}

There are many different models of the medical consultation. Most doctors nowadays will have learned one or more of these at medical school, or later on in their speciality training. The models largely depend on the idea that every consultation has, or should have, a regular pattern involving certain standard sections, each of these lasting several minutes. They generally propose what one might call a "symphonic" structure to the consultation. They see conversations between doctors and patients as meetings that need some kind of pre-determined shape. They regard the doctor as the conductor of the symphony, if not the sole composer.

Thus, for example, one very influential model proposes that every consultation should consist of five parts: initiating the session, gathering information, examination, explanation and planning, and closing the session. ${ }^{1}$ Another popular authority on the consultation suggests that doctors should generally follow a routine of "connecting, summarising, handing over, safety netting and housekeeping". ${ }^{2}$ Other leading teachers offer a variety of names for different parts of the consultation and some models are more ornate than others, but broadly speaking they all share two assumptions: the consultation needs to have a standard structure, and the doctor needs to be in control of it.

\section{TRUE DIALOGUE}

In some ways, all these consultation models are quite enlightened and patient centred. They are certainly an advance on the traditional "clerking" of patients involving a ritual series of questions followed by a full physical examination. They also challenge the idea that patients are simply there to report their symptoms, shut up, and then listen to what their doctors have to say. Yet in other ways the models are problematical. They close off the possibility that each consultation might have infinite possibilities of improvisation. They ignore the principle that true dialogue means that both parties play an equal part in determining its direction: the best conversations, whether social or professional, are unconstrained

Correspondence to: Dr John Launer, London Department of Postgraduate Medical Education, Stewart House, 32 Russell Square, London WC1B 5DN, UK; jlauner@londondeanery.ac.uk by any prior expectations of where they "ought" to go. In linguistic terms, the models are based on a naïve assumption: that the only reason we converse is to state facts, rather than to explore meaning, stake out positions, form relationships or try to evoke a particular response.

One approach that challenges this assumption is based on narrative medicine. ${ }^{3}$ This approach entirely rejects the idea of having a prior set of guidelines for the consultation. Instead, it works on the principle that doctor and patient are coauthors in constructing an agreed story about what has happened, what its significance is, and what if anything needs to be done. At the heart of this model is the idea that humans are innately storytelling creatures: we need conversations with others in order to develop these stories, adapt them to fit our changing experiences, and achieve agreement with others about action. This view of the medical encounter is radical, but we can take it even further. What would happen if we looked at the medical consultation as a fluid encounter, where the final story is determined by the ebb and flow of every single action or utterance made by doctor and patient, and by the interplay between them?

\section{OBSERVING CONSULTATIONS}

To explore this idea, I recently studied a video recording of some consultations, together with two colleagues. As we started to observe the first consultation, we found ourselves drawn into some tiny details of the doctor's behaviour: the way she welcomed the patient into the room, and then allowed him a moment's silence to compose himself. We replayed the opening section again and again, discussing how well she had set the scene for the encounter. We looked at each of the details of movement, gesture, and facial expression. In fact, we spent over an hour reviewing the first three seconds of the recording - and we hadn't even reached the doctor's first question. But while we did so we conceived an entirely new idea for analysing and teaching communication skills. It was to see the doctor's task as managing a series of three second moments. The first job was to get the initial three seconds of the consultation right, and then the next three seconds, and so on through the whole conversation.
Once we had come up with this core idea, we began to elaborate on it. We imagined what it might be like if we taught medical students and junior doctors the importance of the first three seconds of any encounter with a patient. This would mean training them to be alert to every verbal and nonverbal cue that patients brought with them into the consulting room. It would mean making sure that their initial responses were calculated to put patients at their ease, gain their trust and set the scene for a productive consultation. Having established a rapport in these first three seconds, their next task would be quite simple: to focus on the next three seconds, and to continue doing so until the consultation had reached a satisfactory end for both parties.

\section{ACTS OF CREATION}

The notion of the "three second consultation" could change the focus of our attention from the big picture to the little one. It would remind us that getting the diagnosis right can often depend on paying attention to the smallest details of what patients say and do-not just because this is good scientific medicine, but because it encourages them to speak more freely. Such a notion would not, of course, exclude doctors thinking about their own needs as well as those of the patient. Some three second episodes, for example, might need to address the doctor's need to ask for information in order make an accurate diagnosis, or to bring the consultation to a close because of time pressure. Yet at the same time, a reorientation towards these three second moments and their importance would introduce an entirely new and different and more delicate aesthetic into the consultation.

The idea of the "three second consultation" sits well alongside narrative medicine, and adds to it. It could lead us to practise more careful and active listening, and to be more responsive and precise in what we say ourselves. It could help doctors to see their consultations with patients as continuous acts of creation, no more and no less.

\section{Competing interests: None declared.}

Provenance and peer review: Commissioned; not externally peer reviewed.

Postgrad Med J 2009;85:560.

doi:10.1136/pgmj.2009.088948

\section{REFERENCES}

1. Kurtz S, Silverman J. The Calgary-Cambridge observation guides: an aid to defining the curriculum and organizing the teaching in communication training programmes. Med Educ 1996;30:83-9.

2. Neighbour R. The inner consultation. Lancaster: MTP Press, 1987.

3. Launer J. Why narrative? Postgrad Med J 2009;85:167-168. 